\title{
Are life vests worn? A multiregional observational study of personal flotation device use in small boats
}

\author{
Linda Quan, Elizabeth Bennett, Peter Cummings, Michaela N Trusty, Charles D Treser
}

Department of Pediatrics, University of Washington School of Medicine

L Quan

Children's Hospital and Medical Center E Bennett

Department of Epidemiology, University of

Washington School of Public Health and Community Medicine P Cummings

Benton Franklin Health Department M N Trusty

Department of Environmental Health, University of Washington School of Public Health and Community Medicine C D Treser

Correspondence to: Dr Linda Quan, Emergency Department CH04, Children's Hospital and Medical Center, 4800 Sand Point Way NE, Seattle, WA 98105, USA.

\begin{abstract}
Objective-Although life vest use is thought to prevent drowning, their use by boaters has not been described. This study sought to determine the use of personal flotation devices (PFDs) in small boats. Methods-Boaters were observed between April and June 1995 in Washington and Oregon and classified by their age, gender, PFD use, and boat type.

Results-Among 4181 boaters, $25 \%$ wore a PFD. Use was highest in $<5$ year olds $(91 \%)$ and lowest in those over 14 years $(13 \%)$. Those in kayaks were most likely $(78 \%)$ and those in motor boats $(19 \%)$ were least likely to wear a PFD. Females were more likely to wear a PFD than males (relative prevalence $1.5,95 \%$ confidence interval 1.3 to 1.6$)$. When a child less than 15 years was in a boat with an adult, PFD use was $65 \%$ if no adult wore a PFD and $95 \%$ if at least one accompanying adult wore a PFD $(p=0.001)$.
\end{abstract}

Conclusions-Generally, PFD use by boaters was low in the Northwestern US. Efforts to increase PFD use should target adolescents, adults and specific boating populations, especially those in motor boats.

(Injury Prevention 1998;4:203-205)

Keywords: drowning; submersion

Between 1990 and 1995, there were 3143 boat related deaths in the US. Boating drowning rates in Canada, Sweden, Norway, and Finland, are nearly two to sevenfold higher than the US rates. ${ }^{1-4}$ In Canada, boating drownings comprise $40 \%$ of all drownings and primarily involve the recreational use of small boats. Personal flotation devices (PFDs) have the potential to prevent such drownings. Life vests were not being used by $92 \%$ of Canadian and $86 \%$ of US victims of boating drowning, despite recommendations for their use in the US by the Coast Guard, the National Transportation Safety Board, and the American Academy of Pediatrics. ${ }^{356}$ Only one study has described PFD use by recreational boaters, primarily on lakes, in one county in Washington state. ${ }^{7}$ Observations of boaters in several settings and regions are needed to more fully portray patterns of PFD use and thus form the basis for preventive interventions.

This study was conducted to determine the extent of PFD use by recreational boaters in several regions of Washington and Oregon, to describe the characteristics associated with their use, and to identify those who do not wear PFDs so as to focus efforts to increase use.

\section{Methods}

Observations of boaters were conducted in six of the eight emergency medical/trauma regions of Washington State, and the Portland, Oregon area. These regions represent the full range of geographic and climatic variability in the Northwest, from dense forest to desert, and include all types of bodies of water, from Puget Sound to large and small rivers and lakes. Sites were selected using the following criteria: (1) a popular boating recreation area with a high volume of small boat traffic used by families with children; (2) a safe place for an observer to sit. From a list of sites meeting these criteria, using a random selection process, a total of 19 sites were chosen, with several in each region. Sites were classified as lake/reservoir, river, or saltwater (bay or sound).

A total of 19 drowning prevention coordinators and volunteer observers from each of the study regions were trained in classrooms and practiced at on site sessions using an established protocol. ${ }^{7}$ Observers were taught how to use the data collection form and how to classify weather, water conditions, and boat types. Observers were scheduled for 30 to 90 minute observation periods on Fridays through Sundays, from April through June 1995. Observations were conducted between $6 \mathrm{am}$ and $3 \mathrm{pm}$, with numerous observations conducted at each site. All observations were limited to persons in boats less than 19 feet. Persons on personal watercraft (jet skis), rowing sculls, and sailboards were excluded. At the time this study was conducted, PFD use was not legally required of any person in boats in either Washington or Oregon, except for those on personal watercraft (jet skis).

Observation variables included the estimated age ( $<5$ years, 5-14 years, and $>14$ years) and gender of each boater, the type of boat, the weather, wind, and water conditions, and PFD use, defined as wearing a PFD. If observers could not determine with reasonable certainty if the person was wearing a PFD, these boaters were excluded.

DATA ANALYsis

To estimate differences in the prevalence of PFD use among various categories of boaters (such as age group) adjusted for other factors associated with use (such as boat type), we used logistic regression. ${ }^{8}$ Because PFD use is 
Table 1 Observed prevalence of personal flotation device use in seven regions of Washington and Oregon states, 1995

\begin{tabular}{|c|c|c|c|c|}
\hline Category ${ }^{*}$ & No observed & $\begin{array}{l}\text { Prevalence of } \\
\text { PFD use (\%) }\end{array}$ & Relative prevalencet & $\begin{array}{l}95 \% \text { confidence } \\
\text { interval }\end{array}$ \\
\hline All & 4181 & 25.4 & - & - \\
\hline \multicolumn{5}{|l|}{ Age (years) } \\
\hline $0-4$ & 107 & 90.7 & $6.7 \ddagger$ & 6.0 to 7.5 \\
\hline $5-14$ & 840 & 63.5 & $5.3 \ddagger$ & 4.7 to 5.9 \\
\hline$>14$ & 3210 & 13.2 & 1.0 & Reference \\
\hline \multicolumn{5}{|l|}{ Sex } \\
\hline Female & 1450 & 31.4 & 1.5 & 1.3 to 1.6 \\
\hline Male & 2686 & 21.2 & 1.0 & Reference \\
\hline \multicolumn{5}{|l|}{ Boat type } \\
\hline Sailboat & 114 & 50.0 & 2.39 & 2.0 to 2.8 \\
\hline Rowboat & 400 & 27.0 & 1.39 & 1.1 to 1.5 \\
\hline Canoe & 396 & 40.9 & $2.2 \pi$ & 2.0 to 2.5 \\
\hline Kayak & 107 & 77.6 & 5.5 & 4.9 to 6.2 \\
\hline Raft & 96 & 31.3 & 1.19 & 0.8 to 1.5 \\
\hline Motorboat & 2640 & 19.0 & 1.0 & Reference \\
\hline \multicolumn{5}{|l|}{ Water type } \\
\hline Salt water & 354 & 31.6 & $1.1 \neq$ & 0.9 to 1.3 \\
\hline Lake & 2690 & 25.5 & $0.8 \ddagger$ & 0.7 to 1.0 \\
\hline River & 1137 & 23.2 & 1.0 & Reference \\
\hline \multicolumn{5}{|l|}{ Weather } \\
\hline Cloudy & 102 & 20.6 & 0.8 & 0.6 to 1.2 \\
\hline Partly cloudy & 598 & 29.6 & 1.2 & 1.0 to 1.4 \\
\hline Sunny & 3389 & 24.8 & 1.0 & Reference \\
\hline \multicolumn{5}{|l|}{ Temperature $\left({ }^{\circ} \mathrm{F}\right)$} \\
\hline$<65$ & 769 & 26.5 & $1.0 \ddagger$ & 0.8 to 1.4 \\
\hline $65-80$ & 3068 & 25.4 & $1.0 \ddagger$ & 0.9 to 1.2 \\
\hline$>80$ & 285 & 21.8 & 1.0 & Reference \\
\hline
\end{tabular}

* Some missing data for most categories

† Relative prevalence calculated using Mantel-Haenszel stratified relative risk methods.

$\ddagger$ Adjusted for boat type.

I Adjusted for age category. over 14 years wore a PFD, 65\% of the children/youth in the same boat wore a PFD, but if at least one older person wore a PFD, $95 \%$ of the children/youth in the same boat did so. These differences in PFD use according to use by other persons in the same boat were statistically significant $(\mathrm{p}<0.001)$.

Use varied with the type of small boat. It was highest in kayakers $(78 \%)$, followed by sailors $(50 \%)$. Motor boaters were least likely to wear a PFD even after adjusting for age and sex (table 1).

Use did not vary with observed weather conditions or the air temperature. However, all observations were made under conditions of calm or nearly calm water and little wind. Although use varied somewhat by water type and region, most differences were not statistically significant after adjusting for boat type.

\section{Discussion}

This is the first multiregional study describing the use of PFDs in a general population of recreational boaters. Although total use was low $(25 \%)$, this study showed that use was high $(91 \%)$ in children younger than 5 years old in the Northwestern US. PFD use has been mandated for children younger than 6-12 years in boats less than 19 feet in 30 states in the US; however, actual use and effect on drowning mortality have not been evaluated. If the Northwest's PFD use can be generalized to other states, PFD use is so high in this age group without PFD legislation, that the effect of PFD legislation on drowning mortality may be difficult to ascertain in this age group.

This study suggests that further efforts to increase PFD use are needed, particularly by older children and adults. The phenomenon observed in this study of increased child use of a protective device when an adult wore a protective device was also noted in bicycle helmet and in seat restraint use studies. ${ }^{12}{ }^{13}$ The relationship between adult and child use has been attributed to the effect of peer and adult role models and has led to recommendations that adult seat restraint use be required to achieve increased seat restraint use by children. Similarly, efforts to increase PFD use by adults could be used to increase child use.

This study documents that adult PFD use was low. Boating deaths represent a major proportion $(40 \%)$ of drowning deaths in Washington State and boating drowning rates are highest in 15-34 year old males. ${ }^{14}$ Some of the high mortality in these age and gender groups is explained by increased exposure to boating; even in our data, which emphasized areas where children would be in boats, $65 \%$ of boaters were male and $52 \%$ were males over age 14 years. The high boating drowning death rates in adult males have been attributed to increased alcohol use. ${ }^{15}{ }^{16}$ Alcohol use would not explain all boating drowning deaths however, as blood alcohol was detected in only $18 \%$ of adolescent drowning victims in this region and in up to $50 \%$ in adults drowning in other states. ${ }^{17}{ }^{18}$ While PFD use has not been proven to decrease drownings, the very low use $(63 \%)$, but varied with the type of boat. Among persons over 14 years, use was low (13\%) and varied with type of boat and gender. If no one 
of PFDs by adolescents and adults in our study suggests that infrequent PFD use may be a factor in the higher incidence of boat related drowning in these age groups.

Limitations of this study include possible misclassifications of PFD use and user characteristics. However, important misclassification of gender, boat type, or age by PFD use seems unlikely. Non-differential misclassification would have biased our estimates of associations towards the null, and we are not aware of any reason to think that systematic misclassification of these characteristics would be likely. Because some PFDs may have been worn under clothing or incorporated into a jacket, our observations probably underestimated PFD use to some degree.

While the strength of this study is documented use based on direct observations, a remaining limitation includes the limited season of the observations. The observations were conducted early in the spring when children and families might be less likely to be on the water. On the other hand, observation hours and sites were chosen for when and where children would be likely to be in boats; these might have selected a population of boaters more likely to wear PFDs. Although this study was statewide, it is still regional. Thus, its findings can not be generalized to the entire country.

Although we did not assess boat related activities, such as fishing or water skiing, we identified very different patterns of PFD use among boaters. Understanding the relationship between water related recreational activities and use might allow even more specific targeting of PFD use messages. The differing use patterns we observed between kayakers and motor boaters reflect obviously different knowledge and/or attitudes, including perceived risk. Knowledge and attitudes could be further defined among other recreational boater types, such as water skiers and fishermen. With this information, according to theories of social marketing, more specific messages should be created to be more effective..$^{19}$ For instance, better marketing of fishing vests with built in PFDs for fishermen might increase use in this low use population, just as kayak specific PFDs and water skier specific PFDs have been successfully marketed to these recreational groups. Knowledge of user attitudes and targeting messages to specific groups form the mainstay of social marketing in injury prevention; the bicycle helmet campaign is a good example of an effective, successful program that targeted a specific group to increase use of a device that prevents injuries. ${ }^{12}$

\section{Implications for prevention}

PFD use was low in the US Northwest, but use varied by age, gender, and type of boat. In this region, parents put their preschoolers in PFDs when in small boats. Efforts to increase use are needed for those who do not wear PFDs: older youth and adults, and specific boating groups. Boaters in small motor boats are a large group with the lowest prevalence of PFD use. Whether campaigns targeted for these groups to encourage use can be successful seems worthy of investigation.

This study was supported in part by project $\# \mathrm{MCH}$ 534002-01-0 from the Department of Health and Human Services, Health Resources and Services Administration, Maternal and Child Health Bureau, Emergency Medical Services for Children Program.

1 National Center for Health Statistics. Compressed mortality files. http://wonder.cdc.gov/.

2 Cass DT, Ross FI, Grattan-Smith TM. Child drownings: a changing pattern. Med $\mathcal{F}$ Aust 1991;154:711-12.

3 Canadian Red Cross Society. Special research report on drownings among recreational boaters in Canada. Ottawa, ON: Canadian Red Cross Society, 1994

4 Penttila A, Pikkarainen J. Accidents with fatal outcome in Finnish leisure boating 1986-1988. Beitr Gerichtl Med 1990;48: 185-91.

5 National Transportation Safety Board. Recreational boating safety. Washington, DC: National Transportation Safety Board, 1993.

6 American Academy of Pediatrics. Life jackets and life preservers. TIPP, the injury prevention program. Elk Grove, IL: American Academy of Pediatrics, 1992.

7 Treser CD, Trusty MN, Yang PP. Personal flotation device usage: do educational efforts have an impact? $f$ Public Health Policy 1997;18:346-56.

8 Breslow NE, Day NE. Statistical methods in cancer research. Volume 1 -the analysis of case-control studies. Lyon, France: International Agency for Research on Cancer, 1980.

9 Mantel N, Haenszel W. Statistical aspects of the analysis of data from retrospective studies. $\mathcal{F}$ Natl Cancer Inst 1959;22: 719-48.

10 Rothman, KJ. Modern epidemiology. Boston: Little, Brown, 1986.

11 Diggle PJ, Liang KY, Zeger SL. Analysis of longitudinal data. New York: Oxford University Press, 1994

12 Rivara FP, Thompson DC, Thompson RS, et al. Seattle children's bicycle helmet campaign: changes in helmet use and head injury admissions. Pediatrics 1994:93:567-9.

13 Russell J, Kresnow M, Brackbill R. The effect of adult belt laws and other factors on restraint use for children under age 11. Accid Annal Prev 1994;26:287-95.

14 Washington State Department of Health. Drowning in Washington State. Olympia, WA: Washington State Injury ington State. Olympia, WA:

15 Howland J, Mangione T, Hingson R, et al. Pilot survey of aquatic activities and related consumption of alcohol with implications for drowning. Public Health Rep 1990;105: 415-19.

16 Smith G. Drink, drugs and drowning: evaluation of risk factors (abstract). Third International Conference on Injury Prevention and Control: Presentation Abstracts. Melbourne, Australia: National Injury Surveillance Unit, 1996:139-40.

17 Quan L, Gore EJ, Wentz K, et al. Ten year study of pediatric drownings and near drownings in King County, WA: lessons in injury prevention. Pediatrics $1989 ; 83: 1035-40$.

18 Wintemute GJ, Teret SP, Kraus JF, et al. Alcohol and drowning: an analysis of contributing factors and a discussion of criteria for case selection. Accid Ann Prev 1990;22: 291-6.

19 Ogden L, Shepherd M. The prevention marketing initiative: applying prevention of marketing. Centers for Disease Control with William A Smith. Academy of Educational Development and with Porter-Novelli. US Department of Health Human Services. Public Health Services, 1996. 